\title{
Brian G. Barratt-Boyes, KBE (January 13, 1924-March 7, 2006)
}

S R BRIAN PASSED AWAY RECENTLY, LEAVING poignant memories for the many who mourned him. His family, colleagues, friends, patients, and all who learned from him, grieved for what has gone. He also left an enduring reputation as a forward thinking innovator, which will be his legacy for others following his chosen specialty.

Brian was born in Wellington, New Zealand. He was educated at Johnsonville Primary School and Wellington College. Thousands will be grateful that he set aside plans of a career as a concert pianist in favour of medicine. He graduated from the Medical School of Otago University in Dunedin in 1946, and began surgical training in Wellington and Palmerston North. In 1952, he became the first registrar without overseas experience to become a Fellow of the Royal Australasian College of Surgeons. From 1953 to 1955, he worked at the Mayo Clinic, in Rochester, Minnesota, together with John Kirklin, before spending a year as a Nuffield Fellow at the Bristol Royal Infirmary.

After being appointed to a consultancy post in the Cardiothoracic Surgical unit at Green Lane Hospital, Auckland, he achieved a number of firsts. On 3 September, 1958, he pioneered the first use of cardiopulmonary bypass in New Zealand. In 1961, he implanted the first permanent pacemaker unit. On 23 August, 1962, independently but simultaneously with Donald Ross at Guys Hospital, London, he replaced an aortic valve with an allograft. This displayed his propensity for original thought, translated into superb planning and execution. This new treatment of aortic valvar disease was further improved by Brian's technique of inverting the valve to facilitate stitching. In 1965, he became Head of the Cardiothoracic Surgical Unit at Green Lane Hospital. In 1966, he began part time private practice. When offered senior positions at several eminent departments, including ones in London, Edinburgh, and Boston, he eventually turned them down. Whether this was due to reservations about relocating his family, love of New Zealand, or loyalty to the country of his birth, his eventual decision was very much to the advantage of his home country.

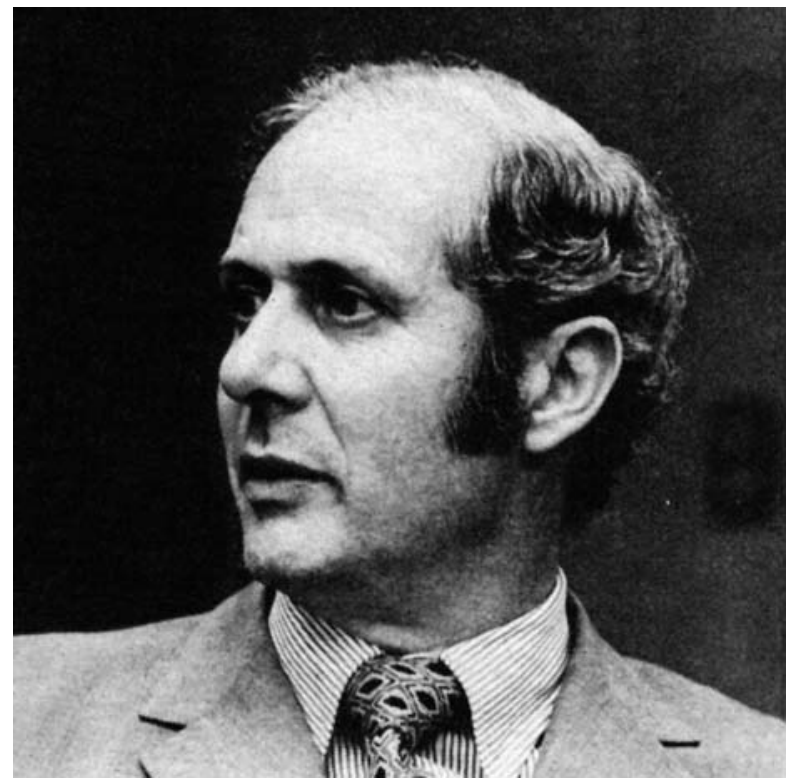

Starting in July, 1969, B-B refined, and successfully used, profound hypothermia with circulatory arrest and limited cardiopulmonary bypass to correct severe congenital cardiac malformations in neonates. Until then, early correction of such severe malformations was rarely attempted in infants, and huge numbers died. The new technique revolutionized the management of congenital cardiac disease in infancy. People who have seen him operate believe his success as a surgeon lay not only with his intelligence and drive to do the best for his patients, his flawless technique, the increased understanding of the complexity of the defects, and the appropriate measures to correct them. There was something else. The graceful confidence of his hands in the operating room perhaps spoke of the movements of the professional musician he may have become. He appreciated that a surgeon does not work in isolation, but rather to obtain excellent results requires expertise from colleagues in paediatric cardiology, cardiac radiology, anaesthesia, nursing, and technical services. Realising a need to comprehend the anatomical complexities of the severe defects, a cardiac morphologist was added to the paediatric cardiology staff at Green Lane Hospital. 
With the excellent results obtained subsequent to performance of cardiac surgery in infants, both B-B and Green Lane Hospital gained international renown and acclaim. This led to numerous visits by overseas visitors, and numerous invitations to speak at international conferences. Such international conferences were organized in Auckland in 1965, in particular to discuss results with homograft aortic valves, in 1972 to highlight the results using profound hypothermia to correct congenital cardiac defects in infancy, and the Asian Pacific Congress, with a large international attendance, in 1987. Brian generated numerous publications, many as a single author, but even more in collaboration with colleagues at Green Lane Hospital.

Fellows from many countries, including North America, Europe, and Asia, came to Green Lane Hospital for further training in cardiac surgery, paediatric cardiac surgery, paediatric cardiology, and cardiac radiology. Brian will be remembered for his challenging stare, the twinkle in his eye, and his stern demand for excellence from colleagues and from himself. In the 1970s, Brian was a prominent participant at international scientific meetings, sometimes provoking controversy, which he handled admirably by speaking in an authoritative and positive manner, and always being well prepared. He was determined to have the best for the unit at Green Lane Hospital, and worked vigorously to achieve this.

Ironically, he required surgical treatment for cardiac disease, including three coronary arterial by-pass procedures, at Green Lane Hospital between 1974 and 1996, a coronary arterial angioplasty, and latterly double valvar replacement in Cleveland two weeks before he died.

He received numerous awards, including appointment as Knight Commander of the Order of the British Empire in 1971, Honorary Fellowship of American College of Surgeons in 1977, Honorary Fellowship of Royal College of Surgeons in 1985, an Honorary Professorship in Surgery at the University of Auckland in 1971, and Honorary Fellowship of American College of Cardiology in 1989, and
Distinguished Alumnus award for the Mayo Clinic in 2005 . His citation called him the greatest physician of the century.

After retiring from surgical practice, Brian at last had time to devote to his family, including the five sons of his first marriage to Norma Thompson, and to Greenhills, the farm he had bought with his mother in 1963. In 1986, he remarried to Sara Monester, and spent more time at the farm, with its idyllic scenic setting. There were many happy family gatherings at Greenhills. Brian remained active, working on the farm, developing an interest in sports, taking up tennis again, and continuing to be involved in research projects. He was collaborating on a long term follow-up study on valvar replacement three weeks before he left for the United States of America for his final surgical procedures.

Brian considered the textbook Cardiac Surgery, published first in 1985, and co-authored with the late John Kirklin, to be his greatest achievement. This book is now in its third edition, and is the standard reference used by cardiac surgeons throughout the world.

The legacy that he leaves is unending, for it includes not just the surgical techniques that he pioneered, but also the younger colleagues whom he imbued with the same dedication and determination to excel. A number have achieved preeminence in the surgical world, particularly in paediatric cardiac surgery.

A. Louise Calder,
Paediatric Cardiologist
Green Lane Paediatric and Congenital Cardiac Service
PCCS Admin
Level 3, Zone 5
Starship Children's Hospital
Private Bag 92024
Auckland 1030
New Zealand
E-mail: LouiseC@adbb.govt.nz

A. Louise Calder, Cardiac Service PCS Admin pital ate Bag 92024 uckland 1030 New Zealand 